\title{
PREDICTION OF LIMITING AMPLITUDES OF CYCLE STRESSES OF WELDED JOINTS WITH STEADY RESIDUAL STRESSES
}

\author{
V.A. DEGTYAREV \\ G.S. Pisarenko Institute for Problems of Strength, NASU \\ 2 Timiryazevskaya Str., 01014, Kiev, Ukraine. E-mail: ips@ipp.kiev.ua
}

\begin{abstract}
In the work the method for determination of diagrams of limiting amplitudes of the cycle of welded joints with steady residual tensile stresses is proposed based on the results of tests of small specimens, which can be considered as an express method for calculation of characteristics of fatigue resistance of welded joints when there is no possibility to carry out full-scale investigations and the appropriate computational dependences are presented. The analysis of literature data for different types of welded joints showed satisfactory correlation of experimental and calculated values of fatigue limits of welded joints of low-carbon and low-alloyed steels of a low strength. It was established that all the diagrams of limiting amplitudes of the cycle of welded joints with steady residual stresses are finished on the line, where each point at different mean stresses of the cycle corresponds to the minimum limiting amplitude of the cycle of welded joint with its value of limiting steady residual stress, which provides realization of limiting stresses of cycle. It was shown that if at the low values of steady residual stresses the relative reduction in fatigue limits of butt welded joints of steels of different strength is occurred almost for the same value, then with their increase, the reduction of fatigue limit of steel with higher mechanical characteristics is more significant. 23 Ref., 1 Table, 3 Figures.
\end{abstract}

Keywords : amplitude of cycle stresses, mean stress of cycle, yield strength, steady residual stress, fatigue limit, diagram of limiting amplitudes of cycle

Numerous investigations indicate, that among the whole number of factors which determine the load-carrying capacity of welded metal structures of different purpose, welding residual stresses (RS) play a significant role $[1,2]$. In the greatest extent the influence of tensile RS on the fatigue limits is revealed at symmetric loading cycle and is considerably reduced due to a more significant relaxation with the increase in the level of operating stresses or the ratio of asymmetry cycle $R_{\sigma}$ [3-5]. As far as the reduction of RS occurs mainly during several tens of cycles of loading to a specified value, then the set value of residual stresses $\sigma_{\text {res }}^{\mathrm{s}}$ plays the main role in decreasing the fatigue limit of welded joint $[6,7]$, the method of determination of which is presented in the work [8]. This should be reflected on the character of diagrams of limiting stresses of the cycle (DLSC) [8] or limiting amplitudes of the cycle (DLAC). If for welded joints without RS the limiting amplitude $\sigma_{\mathrm{a}}$ depends on the mean stress of the cycle $\sigma_{\mathrm{m}}$, then for all the types of welded joints of different strength with high RS such dependence is not observed. As the determination of diagrams is based, as a rule, only on the stresses from external load, not accounting for RS, then the determination of DLAC of welded joints, containing different level of $\sigma_{\text {res }}^{\mathrm{s}}$, can be important for artificial control of residual stresses during prediction of limiting state of weld-

(C) V.A. DEGTYAREV, 2016 ed metal structures. Undoubtedly, the most valid data can be obtained during tests of full-scale elements of metal structures containing the different level of $\sigma_{\text {res }}^{\mathrm{s}}$. However, due to considerable material costs a number of experimental investigations of influence of the level $\sigma_{\text {res }}^{\mathrm{s}}$ on fatigue resistance of welded joints is extremely limited. Therefore, the development of the method for determination of DLSC or DLAC of welded joints with RS according to the results of tests of small specimens is urgent. Earlier, in the work [9] the method for determination of fatigue limits of welded joints with high RS was proposed based on the results of tests of small specimens considering the established fact of intersection of diagrams of limiting stresses of cycle. In the works $[8,10]$ the determination of diagrams of limiting stresses of the cycle of welded joints with different value of initial RS was proposed based on the results of small specimens tests and the level of limiting initial residual stress was calculated which provides realization of the limiting cycle of stresses. At the same time the methods proposed until now can not provide an unambiguous answer, where the diagrams of limiting amplitudes of the cycle of welded joints with different value of steady residual stresses are finished and why they are parallel to the diagram of limiting amplitudes of the cycle of specimens without RS. Moreover, the proposed methods did not find experimental confirmation for different types of weld- 
ed joints, and it is unclear whether they can be applied to welded joints with different mechanical properties. In this regard, in the present work the calculated method for determination of limiting amplitudes of cycle of welded joints with different levels of steady residual tensile stresses was grounded based on the results of tests of small specimens without RS at their comparison with experimental data and the cause was revealed explaining why diagrams of limiting amplitudes of the cycle of welded joints with different value $\sigma_{\text {res }}^{\mathrm{s}}$ are finished on the line having the same value of minimum limiting amplitude of cycle, independent of the mean stress of cycle.

Analysis of obtained results. During tests at a single value $R_{\sigma}$ the diagram of limiting amplitudes of cycle of welded specimens without residual stresses (Figure 1, line 1) is usually represented in the form:

$$
\sigma_{\mathrm{a}}=\sigma_{-1}-\psi_{\sigma} \cdot \sigma_{m}^{\prime},
$$

where $\sigma_{-1}$ is the fatigue limit of welded joint at a symmetric cycle of stresses; $\sigma_{\mathrm{m}}$ is the actual value of mean stress of cycle; $\psi_{\sigma}$ is the coefficient of sensitivity to the asymmetry of the cycle of stresses, which is determined at a known value of ultimate strength of the material $\sigma_{t}$ by the ratio of $\sigma_{-1} / \sigma_{f}$

According to this dependence the limiting amplitude of stresses $\sigma_{\mathrm{a}}$ depends on the mean stress $\sigma_{\mathrm{m}}$. It should be noted that in the present work the influence of the theoretical coefficient of stress concentration was not considered because of determination of DLSC or DLAC, accepted in the work [11], only on the action of nominal stresses. The analysis of results of tests of different types of welded joints with high residual stresses, obtained experimentally, shows that $\sigma_{\mathrm{a}}$ does not depend on $\sigma_{\mathrm{m}}$ in this case (line 3). [4] With the growth of mean stress or the asymmetry coefficient of the cycle, the difference between the limiting amplitudes of welded specimens with residual stresses and without them is reduced and approximately in the point, corresponding to the yield strength $\sigma_{y}$ of the material, the lines 1 and 3 are intersected $[8,12]$. In this case the limiting amplitude reaches its minimum value $\sigma^{\mathrm{l}}$ at the mean stress $\sigma_{\mathrm{mY}}(\mathrm{y}, \mathrm{A})$ and has the same value for welded joints without RS and with them. Thus, the value $\sigma^{1}$ may be determined using calculation method at the known value of fatigue limit of welded joint without RS in the following form:

$$
\sigma_{\mathrm{a}}^{n}=\sigma_{-1}-\psi_{\sigma} \cdot \sigma_{\mathrm{mY}} \cdot
$$

Taking into account that $\sigma_{\mathrm{a}}^{\mathrm{l}}=\sigma_{\mathrm{Y}}-\sigma_{\mathrm{mY}}$ having substituted it to (2), it can be written that

$$
\sigma_{\mathrm{mY}}=\frac{\sigma_{\mathrm{Y}}-\sigma_{-1}}{1-\psi_{\sigma}} .
$$

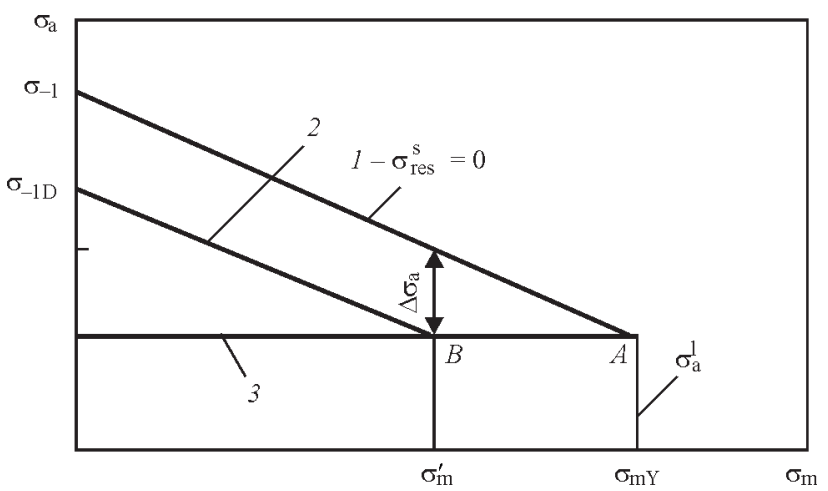

Figure 1. Scheme for determination of diagrams of limiting amplitudes of cycle of welded joints with steady residual stresses: 1 - diagram of limiting amplitudes of cycle of welded specimens without residual stresses; 2 - calculated diagram of limiting amplitudes of cycle of welded specimens with steady residual stress; 3 - diagram of minimum limiting amplitudes of cycle

Thus, the dependence for determination of $\sigma_{\mathrm{a}}^{\mathrm{l}}$ can be represented as

$$
\sigma_{\mathrm{a}}^{1}=\frac{\sigma_{-1}-\psi_{\sigma} \sigma_{\mathrm{Y}}}{1-\psi_{\sigma}} .
$$

The earlier analysis of literature data [12] showed, that if we present the results of investigations of different types of welded joints of low-carbon and low-alloyed steels with the steady residual stresses $\sigma_{\text {res }}^{\mathrm{s}}$ in the form of the sum of the limiting amplitude of the cycle $\sigma_{R \mathrm{D}}$ of such a joint and the steady residual stress, which is considered as a static component, i. e. $\left(\sigma_{R \Sigma}=\right.$ $\left.=\sigma_{R \mathrm{D}}+\sigma_{\mathrm{res}}^{\mathrm{s}}\right)$, and the mean stress, respectively, in the form of $\sigma_{\mathrm{m} \Sigma}^{\mathrm{res}}=\sigma_{\mathrm{m}}+\sigma_{\mathrm{r}}^{\mathrm{s}}$, then independently of the level of residual stress all the points are satisfactorily lie on DLSC of welded joints without residual stresses, described by the dependence of Goodman [11]

$$
\sigma_{\max }=\sigma_{-1}+\left(1-\psi_{\sigma}\right) \sigma_{m}^{\prime} .
$$

Moreover, when the sum of the initial residual stresses and stresses from external load, i. e. the fatigue limit, does not reach the yield strength of the material, the steady RS correspond to the initial ones and in this case the summed stresses are located at the inclined area of a diagram. After $\sigma_{R \Sigma}$ reaches the yield strength of the material, the relaxation of the initial RS to the steady level (maximum level) occurs and, in spite of the different values $\sigma_{\text {res }}^{\mathrm{s}}$, obtained depending on the stresses from external load, the realization of a single limiting cycle of stresses is provided. In this case, the results of tests of specimens with different value of the steady residual stresses can be appropriately described by the equation in the form:

$$
\sigma_{R \Sigma}=\sigma_{-1}+\left(1-\psi_{\sigma}\right) \cdot\left(\sigma_{\mathrm{m}}^{\prime}+\sigma_{\text {res }}^{\mathrm{s}}\right) .
$$

In the absence of RS the equation (6) acquires the form (5). It should be noted that the given expression is valid under the condition that the influence of the steady residual stress and mean stress from the ex- 
ternal load on the fatigue resistance of welded joints is identical. Consequently, the sensitivity of welded joints with different value of steady residual stresses to the loading asymmetry must also be the same. In addition, one should bear in mind that the expression for determination of steady residual stress bears an idealized character and provides an approximate calculation [8]. It is connected with the fact that during cyclic deformation, when total stresses, as a rule exceed the elastic limit of material as a result of accumulation of inelastic deformations, the cycle-by-cycle reduction of the initial RS occurs. Therefore, to determine it more accurately, the additional experimental information or information about inelastic deformation of the investigated material [13] or the diagrams of the limits of cyclic creep at the preliminary specified tolerance for residual deformation, providing reduction of RS to the predetermined value, are required [14]. However, in practice the widespread use of the mentioned dependence is connected with the accessibility of rapid determination of values included in it.

The fact of presence of a single diagram allows, firstly, selecting the required modes of loading the welded structure to achieve the preset $\sigma_{\text {res }}^{\mathrm{s}}$ in it, and, secondly, determining the diagrams of limiting stresses of the cycle or limiting amplitudes of the cycle of welded joints with the preset value $\sigma_{\text {res }}^{\mathrm{s}}$ based only on the stresses from external load using the results of tests of welded joints without RS. Taking into account that $\sigma_{\mathrm{aD}}=\sigma_{R \Sigma}-\sigma_{\mathrm{m} \Sigma}$, the dependence for determination of DLAC of welded specimens with a preset value of steady residual stresses (Figure 1, line 2) can be written as

$$
\sigma_{\mathrm{aD}}=\sigma_{-1}-\psi_{\sigma} \cdot\left(\sigma_{\mathrm{m}}^{\prime}+\sigma_{\mathrm{res}}^{\mathrm{s}}\right),
$$

or

$$
\sigma_{\mathrm{aD}}=\sigma_{-1}\left(1-\frac{\sigma_{\mathrm{m}}^{\prime}+\sigma_{\mathrm{res}}^{\mathrm{s}}}{\sigma_{?}}\right) .
$$

In this case, the inclined area of the diagram after the joint solution of equations (1) and (7) is displaced to the value $\Delta \sigma=\psi_{\sigma} \sigma_{\text {res }}^{\mathrm{s}}$ in parallel relatively to DLAC of welded specimens without RS.

The mean stress from the external load, under the action of which the preset value $\sigma_{\text {res }}^{s}$ remains in welded specimen, can be easily determined by solving the equation (7) relatively to $\sigma_{\mathrm{m}}$, taking into account that

$$
\begin{aligned}
& \psi_{\sigma}=\left(\sigma_{-1}-\sigma_{\mathrm{a}}^{\mathrm{l}}\right) / \sigma_{\mathrm{mY}} \\
& \sigma_{\mathrm{m}}^{\prime}=\frac{\sigma_{-1}-\sigma_{\mathrm{aD}}}{\psi_{\sigma}}-\sigma_{\text {res }}^{\mathrm{s}} .
\end{aligned}
$$

Particularly interesting is the answer to the question, where DLAC of welded joints with the preset value $\sigma_{\text {res }}^{\mathrm{s}}$ is finished. After conversion of the equa- tion (2) relatively to $\sigma_{\mathrm{mY}}$ and the combined solution of equations (2) and (9) we shall obtain finally that the mean stress for welded specimens with the steady residual stress, which in this case will be limiting, and thus $\sigma_{\mathrm{aD}}=\sigma_{\mathrm{a}}^{1}$ is displaced along the line 3 to the value $\Delta \sigma_{\mathrm{m}}=\sigma_{\mathrm{mY}}-\sigma_{\mathrm{m}}=\sigma_{\text {res }}^{\mathrm{s}}(\mathrm{p} \cdot \mathrm{B})$. Thus, each point at this straight line at different mean stresses of the cycle corresponds to the minimum limiting amplitude of the cycle of welded joint with its value of limiting steady residual stress, which provides finally the realization of the limiting cycle of stresses.

As an example, in the Table for different types of welded joints made of steels of different strength, the literature data are given experimentally obtained on the basis of $2 \times 10^{6}$ cycles of fatigue limits at a symmetric loading cycle at different values $\sigma_{\text {res }}^{\mathrm{s}}$ and their calculated values. The Table presents also the experimental values of fatigue limits of welded joints without residual stresses. The comparison of results of calculated evaluation of the influence of steady RS on fatigue limits of welded joints according to the proposed methods and experimental data showed a good correlation for welded joints of low-carbon and low-alloyed steels of a low strength. It is seen that the difference is within the range of 3-11 MPa, which corresponds to the error of 6-20\%. Concerning the welded joint of low-alloyed steel 10KhSND, it is seen that due to a low fatigue limit, a small difference in the calculated and experimental values leads to a noticeable error. Moreover, the analysis of Table data showed that for high-strength steels (14KhMDFR) the proposed methods of calculation lead to a significant error. This is apparently connected with the fact that, having an elongated character of the diagrams of limiting amplitudes in welded joints of such steels, such processes are probably developed at the increase in mean stress with the accumulation of cycles, which can increase not only the strength of metal, but also increase the limiting value of stresses amplitude in this case. In this regard, the diagrams of limiting stresses or amplitudes may have a hyperbolic character [23]. It shows once again that hypothetical dependences of the type of Smith or Hay, describing the behavior of diagrams of the investigated materials, which are often used in the literature, should be considered as approximate, not reflecting the whole complexity and multifactorial nature of fatigue of the welded joints. Nevertheless, the analysis of the results allows concluding that under certain difficulties in carrying out fatigue tests or absence of experimental data the presented methods can be used as an express method for calculation determination of fatigue characteristics of welded joints of low-carbon and low-alloyed steels with a different value $\sigma_{\text {res }}^{\mathrm{s}}$. 
Comparison of experimental and calculation values of fatigue limits of different types of welded joints produced of different strength materials $(\mathrm{MPa})$

\begin{tabular}{|c|c|c|c|c|c|c|c|c|}
\hline Steel, type of joint & $\sigma_{y}, \mathrm{MPa}$ & $\sigma_{\text {res }}^{\mathrm{s}}, \mathrm{MPa}$ & $\sigma_{\mathrm{a}}^{\mathrm{l}}, \mathrm{MPa}$ & $\sigma_{\mathrm{m}}, \mathrm{MPa}$ & $\sigma_{-1}^{\mathrm{e}}, \mathrm{MPa}$ & $\sigma_{-1}^{\mathrm{P}}, \mathrm{MPa}$ & $\Delta$ & Reference \\
\hline St. 3, cruciform & 300 & $\begin{array}{c}0 \\
127\end{array}$ & $\begin{array}{c}21.5 \\
-\end{array}$ & $\begin{array}{l}278.5 \\
151.5\end{array}$ & $\begin{array}{c}40 \\
28.5\end{array}$ & 31.5 & -3 & [15] \\
\hline M16S, butt & 237 & $\begin{array}{c}0 \\
160\end{array}$ & $\begin{array}{l}72 \\
-\end{array}$ & $\begin{array}{c}165 \\
0\end{array}$ & $\begin{array}{c}116 \\
76\end{array}$ & 72 & 4 & [16] \\
\hline 14KhMDFR, butt & 600 & $\begin{array}{c}0 \\
450\end{array}$ & $\begin{array}{c}20 \\
-\end{array}$ & $\begin{array}{c}580 \\
0\end{array}$ & $\begin{array}{c}110 \\
70\end{array}$ & 40 & 30 & $\begin{array}{c}{[17]} \\
{[4]}\end{array}$ \\
\hline Low-carbon, butt & 300 & $\begin{array}{c}0 \\
230\end{array}$ & $\begin{array}{l}56 \\
-\end{array}$ & $\begin{array}{c}244 \\
15\end{array}$ & $\begin{array}{c}108 \\
69\end{array}$ & 59 & 10 & {$[8]$} \\
\hline 09G2S, with deposits & 317 & $\begin{array}{c}0 \\
150\end{array}$ & $\begin{array}{c}60 \\
-\end{array}$ & $\begin{array}{l}257 \\
107\end{array}$ & $\begin{array}{c}120 \\
95\end{array}$ & 85 & 10 & [18] \\
\hline Low-carbon with transverse fillet welds & 240 & $\begin{array}{c}0 \\
175 \\
\end{array}$ & $\begin{array}{c}68 \\
- \\
\end{array}$ & $\begin{array}{c}172 \\
0\end{array}$ & $\begin{array}{l}80 \\
60\end{array}$ & 68 & -8 & [19] \\
\hline St.3, welding-on of transverse stiffeners & 260 & $\begin{array}{c}0 \\
220\end{array}$ & $\begin{array}{c}40 \\
-\end{array}$ & $\begin{array}{c}220 \\
0\end{array}$ & $\begin{array}{l}80 \\
40\end{array}$ & 38 & 2 & $\begin{array}{c}{[20]} \\
{[4]}\end{array}$ \\
\hline $10 \mathrm{KhSND}$, welding-on of transverse stiffeners & 442 & $\begin{array}{c}0 \\
410\end{array}$ & $\begin{array}{c}30 \\
-\end{array}$ & $\begin{array}{c}412 \\
0\end{array}$ & $\begin{array}{l}99 \\
20\end{array}$ & 30 & -10 & $\begin{array}{c}{[21]} \\
{[4]}\end{array}$ \\
\hline 09G2S, butt & 339 & $\begin{array}{c}0 \\
270\end{array}$ & $\begin{array}{l}64 \\
-\end{array}$ & $\begin{array}{c}276 \\
0\end{array}$ & $\begin{array}{c}136 \\
75\end{array}$ & 64 & 11 & $\begin{array}{c}{[22]} \\
{[4]}\end{array}$ \\
\hline 09G2, butt & 343 & $\begin{array}{c}0 \\
160\end{array}$ & $\begin{array}{l}67 \\
-\end{array}$ & $\begin{array}{c}276 \\
-\end{array}$ & $\begin{array}{c}155 \\
99\end{array}$ & 105 & -6 & [9] \\
\hline $\begin{array}{l}\text { St. 3(killed), overlapped with flange weld and } \\
\text { welding around the contour }\end{array}$ & 230 & $\begin{array}{c}0 \\
195\end{array}$ & $\begin{array}{c}27 \\
-\end{array}$ & $\begin{array}{c}203 \\
-0\end{array}$ & $\begin{array}{l}54 \\
35\end{array}$ & 28 & 7 & $\begin{array}{l}{[1]} \\
{[4]}\end{array}$ \\
\hline
\end{tabular}

To determine the asymmetry coefficient of cycle at which the residual stresses are relaxed completely, it is enough to write that

$$
\sigma_{R \mathrm{D}}=\frac{2 \sigma_{\mathrm{a}}^{1}}{1-R_{\sigma}}=\sigma_{\mathrm{Y}} .
$$

Substituting the expression (2) to (10), after some transformations it can be established that intersection of diagrams of limiting amplitudes of the cycle of welded joints without residual stresses and with the steady level of residual stresses (Figure 1, lines 7 and 3) will occur at

$$
R=1-\frac{2\left(\sigma_{-1}-\psi_{\sigma} \sigma_{\mathrm{mY}}\right)}{\sigma_{\mathrm{Y}}} .
$$

It is easy to determine the asymmetry coefficient of the cycle, at which intersection of diagrams of limiting amplitudes of the cycle of welded joints with the set value of residual stresses occurs with the line 3 , knowing that $\sigma_{\mathrm{aD}}=\sigma_{\mathrm{a}}^{\mathrm{l}}$ and $\sigma_{\mathrm{RD}}=\sigma_{\mathrm{aD}}+\sigma_{\mathrm{m}}=\sigma_{\mathrm{Y}}-\sigma_{\mathrm{mY}}+$ $+\sigma_{\mathrm{m}}$. Substituting the expression (7) to (10), it can be written that

$$
\sigma_{\mathrm{Y}}-\sigma_{\mathrm{mY}}+\sigma_{\mathrm{m}}^{\prime}=\frac{2\left(\sigma_{-1}-\psi_{\sigma} \sigma_{\mathrm{res}}^{\mathrm{s}}-\psi_{\sigma} \sigma_{\mathrm{m}}^{\prime}\right)}{1-R} .
$$

After some transformations we will obtain that

$$
R=1-\frac{2\left(\sigma_{-1}-\psi_{\sigma} \sigma_{\mathrm{mY}}\right)}{\sigma_{\mathrm{Y}}-\sigma_{\mathrm{res}}^{\mathrm{s}}} .
$$

Thus, the higher the value $\sigma_{\text {res }}^{\mathrm{s}}$, the lower the value $R_{\sigma}$ at which intersection of diagrams of limiting amplitudes of the cycle of welded joints occurs with the line 3. It should be noted that the degree of influence of RS on fatigue resistance of welded joints depends not only on their level, but also on the parameters of external load as well as mechanical characteristics of the used materials. The mentioned calculated ratios allow evaluating not only the influence of RS on fatigue limits, but also calculating the fatigue strength of welded elements of metal structures at artificial regulation of residual stresses in them.

As an example of calculation according to the proposed methods, Figure 2 presents a series of diagrams of limiting amplitudes of the cycle of butt welded joints of low-carbon steel St.3 (killed) $\left(\sigma_{\mathrm{y}}=300\right.$ $\mathrm{MPa})$ and low-alloyed steel 09G2S $\left(\sigma_{\mathrm{y}}=340 \mathrm{MPa}\right)$ with different level of steady residual stresses. It is seen that the diagrams are parallel not only between themselves but also DLAC of welded joints without RS. Moreover, their displacement relatively to each other occurs for the value equal to $\Delta \sigma_{\mathrm{a}}=\psi_{\sigma} \sigma_{\text {res }}^{\mathrm{s}}$. All the diagrams are finished at the points located on a straight line 6, which is parallel to the mean stress of the cycle. It means that regardless of the level of the steady residual stresses, all the diagrams of limiting amplitudes of the cycle have the same value of the minimum limiting amplitude $\sigma_{\mathrm{a}}^{\mathrm{l}}$ equal to $56 \mathrm{MPa}$ for low-carbon and $64 \mathrm{MPa}$ for low-alloyed steels at different value of mean stress of the cycle, and it does not contradict to the literature data [10]. In this connection it can be noted that in reality the mentioned 

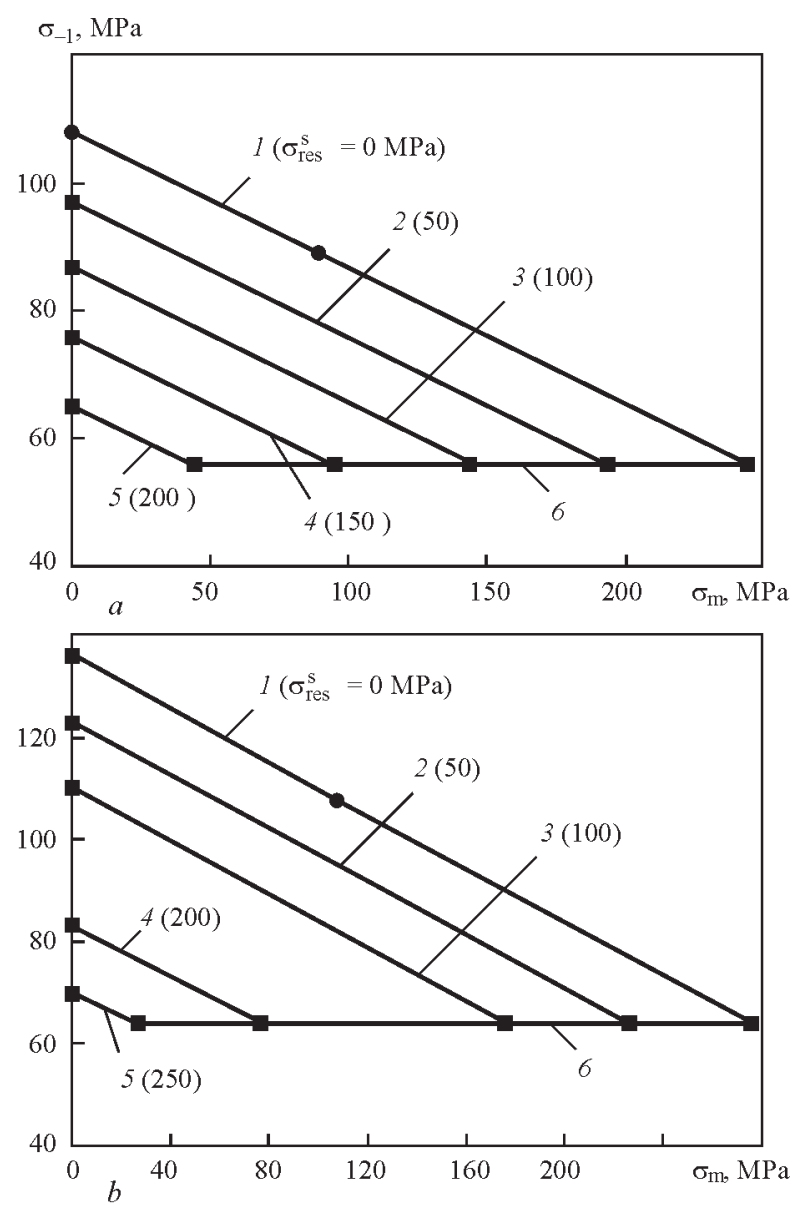

Figure 2. Diagrams of limiting amplitudes of cycle of butt welded joints of low-carbon steel St. 3 (killed) (a) and low-alloyed steel 09G2S (b): 1 - without residual stresses; $2-5$ - with specified level of residual stresses; 6 - diagram of minimum limiting amplitudes of cycle $(\bullet, \mathbf{-}-$ experimental and calculated values of fatigue limits, respectively)

straight line 6 is not the diagram of limiting amplitudes of the cycle of welded joints with high RS, as it is usually called at the present time in the literature [4] but most probably the diagram of minimum limiting amplitudes of the cycle (DMLAC), where each point on the mentioned straight line is nothing else than a totality of fatigue limits of welded joint with its value of limiting steady residual stress, which provides the realization of the limiting cycle of stresses. Regarding the diagrams of limiting stresses of the cycle, then it is better to call such a straight line as the diagram of minimum limiting stresses of the cycle with its value of limiting $\sigma_{\text {res }}^{\mathrm{s}}$.

The sensitivity of butt welded joints of steels of different strength to the value $\sigma_{\text {res }}^{\mathrm{s}}$ is illustrated in Figure 3. Taking into account the experimental and calculated data, the Figure presents the dependences of changes in their fatigue limits at symmetric loading cycle on the value of steady residual stresses in relative coordinates. From the analysis of Figure it follows that at low values $\sigma_{\text {res }}^{\mathrm{s}}$ the relative reduction of fatigue limits of welded joints $\sigma_{-1 \mathrm{D}}$ occurs almost

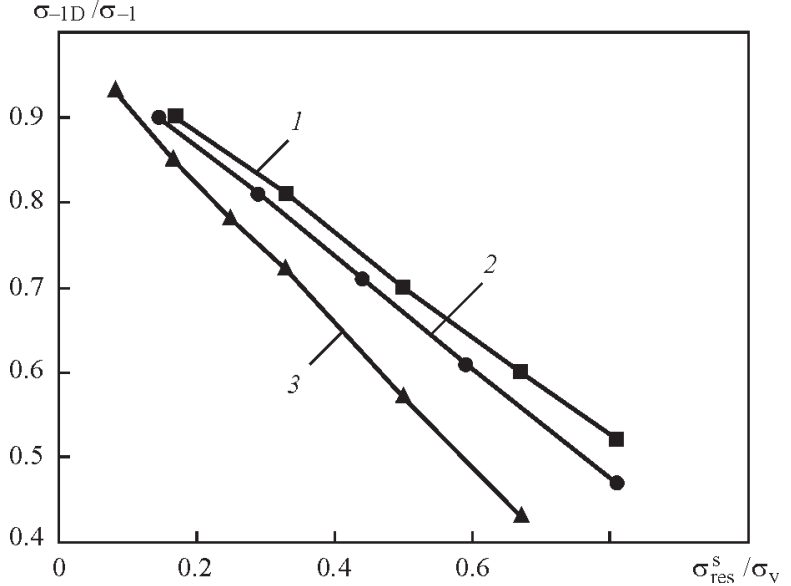

Figure 3. Influence of steady residual stresses on fatigue limits of butt welded joints: 1 - low-carbon steel St. 3(killed) $\left(\sigma_{y}=\right.$ $=300 \mathrm{MPa}) ; 2$ - low-alloyed steel 09G2S $\left(\sigma_{\mathrm{y}}=340 \mathrm{MPa}\right) ; 3-$ low-alloyed high-strength steel 14KhMDFR $\left(\sigma_{\mathrm{y}}=600 \mathrm{MPa}\right)$

to the same value. However, with increase in $\sigma_{\text {res }}^{\mathrm{s}}$, the reduction of fatigue limit of welded joints of steel with higher mechanical characteristics is more significant as a result of which the curves diverge. For example, at the value $\sigma_{\text {res }}^{\mathrm{s}}$ equal to $0.5 \sigma_{\mathrm{y}}$, the reduction in fatigue limit of welded joint of low-carbon and high-strength steel occurs at 30 and $43 \%$, respectively. If the twice reduction of fatigue strength of welded joint of steel 14KhMDFR is achieved at the value $\sigma_{\text {res }}^{\mathrm{s}}$ equal to $0.6 \sigma_{\mathrm{y}}$, then for the welded joint of steel St. 3(killed) it is achieved almost at $0.85 \sigma_{\mathrm{y}^{\prime}}$ It can be noted that the practical value of the Figure consists in the presented possibility to determine the selection of steel at the presence of steady residual stresses in the elements of metal structures of the known value without additional labor consuming investigations of large-sized specimens.

Thus, the presented methods can be considered as an express method for calculation of characteristics of fatigue resistance of welded joints, containing different level of steady residual stresses when there is no possibility for full-scale experimental investigations.

\section{Conclusions}

1. The method for determination of diagrams of limiting amplitudes of cycle of welded joints of low-carbon and low-alloyed steels of low strength with the steady residual stresses was proposed and experimentally confirmed.

2. The regularity of change in fatigue limits of butt welded joints of different strength steels was established based on their mechanical characteristics and steady residual stress.

1. Duchinsky, B.N. (1956) Endurance of components of welded bridge structures in fluctuating and alternate stresses. In: Ex- 
amination of strength of welded bridge structures. Issue 20 . Moscow: Transzheldorizdat.

2. Okerblom, N.O. (1950) Welding stresses in metal structures. Moscow; Leningrad: Mashgiz.

3. Hobbacher, A. Recommendations on fatigue of welded components. IIW Doc. X-1539-94-XV-845-94.

4. Trufyakov, V.I. (1973) Fatigue of welded joints. Kiev: Naukova Dumka.

5. Bajkova, I.P. (1969) Influence of external tensile load on welded strains and stresses. Svarochn. Proizvodstvo, 6, 3-5.

6. Ryakhin, V.A., Moshkarev, G.N. (1984) Service life and stability of welded structures of construction site and road making machines. Moscow: Mashinostroenie.

7. Dawson, R. (1980) Vibration stress relieving and study of its efficiency. Teoreticheskie Osnovy, 102(2), 1-9.

8. Trufyakov, V.I., Kudryavtsev, Yu.F., Mikheev, P.P. (1988) On effect of residual stresses on fatigue resistance of welded joints. Avtomatich. Svarka, 2, 1-4.

9. Shulginov, B.S., Degtyarev, V.A., Matveev, V.V. (1984) On limit cycle stresses of welded joints with high residual stresses. Problemy Prochnosti, 3, 58-61.

10. Trufyakov, V.I., Mikheev, P.P., Kudryavtsev, Yu.F. (1988) Change of fatigue resistance of welded joints under action of residual stresses. In: Proc. of 3rd All-Union Symp. on Residual Technological Stresses (Kutaisi, October, 1988). Moscow: In-te for Problems in Mechanics, 358-364.

11. Serensen, S.V., Kogaev, V.P., Shnejderovich, R.M. (1975) Load-carrying capacity and strength calculations of machine parts. Moscow: Mashinostroenie.

12. Degtyarev, V.A., Shulginov, B.S. (2008) Assessment of limit cycle stresses for welded joints with high residual stresses by testing results of small-sized specimens without residual stresses. Problemy Prochnosti, 2, 66-81.

13. Troshchenko, V.T., Tsybanev, G.V., Gryaznov, B.A. et al. (2009) Fatigue of metals. Influence of surface state and contact interaction. In: Strength of materials and structures, Vol. 2. Kiev: IPS.

14. Degtyarev, V.A., Vlasenko, V.I. (1992) Application of complex diagram of limit cycle stresses for vibration treatment purpose. Tyazholoe Mashinostroenie, 8, 27-30.

15. Navrotsky, D.I. (1961) Strength of welded joints. Moscow: Mashgiz.

16. Trufyakov, V.I. (1956) About the role of residual stresses in reduction of endurance of welded joints. Avtomatich. Svarka, 5, 90-103.

17. Myunze, V.Kh. (1968) Fatigue strength of steel welded structures. Moscow: Mashinostroenie.

18. Trufyakov, V.I., Gushcha, O.I., Trotsenko, V.P. (1976) Change of residual stresses in stress concentration zones at cyclic loading of welded joints. Problemy Prochnosti, 12, 14-17.

19. (1991) Guidelines. Engineering safety. Probabilistic method of calculation of welded structures fatigue. Standard RD 50694-90. Valid from 01.07.91. Moscow: Standart.

20. Kudryavtsev, I.V., Naumchenkov, N.E. (1976) Fatigue of welded structures. Moscow: Mashgiz.

21. Popova, M.M. (1978) Fatigue resistance of 14Kh2GMR steel welded joints. Metal structures of crane and examination of conveyors. Transact. LPI, 362, 70-74.

22. Eregin, L.P., Naumchenkov, N.E. (1971) Static and fatigue strength of butt welded joints of 09G2S steel made on ground and roll scale. Svarochn. Proizvodstvo, 11, 36-39.

23. Oding, I.L. (1962) Admissible stresses in machine-building and cyclic strength of metals. Moscow: Mashgiz.

Received 10.05.2016 